\title{
Triptolide-induced apoptosis in non-small cell lung cancer via a novel miR204-5p/Caveolin-1/Akt-mediated pathway
}

\author{
Brian J. Philips ${ }^{1}$, Ajay Kumar ${ }^{1}$, Sarah Burki ${ }^{1}$, John P. Ryan ${ }^{1}, K_{\text {Kentaro Noda }}{ }^{\text {and }}$ \\ Jonathan D'Cunha² \\ ${ }^{1}$ Division of Lung Transplantation and Lung Failure, Department of Cardiothoracic Surgery, University of Pittsburgh, \\ Pittsburgh, PA, USA \\ ${ }^{2}$ Department of Cardiothoracic Surgery, Mayo Clinic, Phoenix, AZ, USA
}

Correspondence to: Jonathan D'Cunha, email: DCunha.Jonathan@mayo.edu

Keywords: triptolide; lung cancer; caveolin-1; miR204-5p; apoptosis

Received: February 08, $2020 \quad$ Accepted: April 14, $2020 \quad$ Published: July 14, 2020

Copyright: Philips et al. This is an open-access article distributed under the terms of the Creative Commons Attribution License 3.0 (CC BY 3.0), which permits unrestricted use, distribution, and reproduction in any medium, provided the original author and source are credited.

\section{ABSTRACT}

Lung cancer is one of the most prevalent malignancies world-wide with non-small cell lung cancer (NSCLC) comprising nearly $\mathbf{8 0} \%$ of all cases. Unfortunately, many lung cancer patients are diagnosed at advanced stages of the disease with an associated poor prognosis. Recently, the Chinese herb root extract Triptolide/Minnelide (TL) has shown significant promise as a therapeutic agent for NSCLC treatment both in vitro and in vivo. The aim of this study was to investigate the underlying mechanism(s) of action regarding TL-induced cytotoxicity in NSCLC. We demonstrate that triptolide treatment of A549 and H460 NSCLC cells decreases Caveolin-1 (CAV-1) mRNA/protein expression, resulting in activation of the Akt/Bcl-2-mediated mitochondrial apoptosis pathway. CAV-1 down-regulation was triggered by Micro-RNA 204-5p (miR204-5p) up-regulation and could be significantly blocked by pre-treatment with both Sirt-1/ Sirt-3 specific siRNA and SIRT-1/SIRT-3 enzyme inhibitors, EX-527 and nicotinamide. Overall, our results provide evidence for a novel mechanism by which TL exerts its cytotoxic effects on NSCLC via CAV-1 down-regulation. Furthermore, these findings demonstrate a pivotal role for TL induction of the Akt/Bax pathway in apoptosis of human lung cancer.

\section{INTRODUCTION}

Triptolide (TL), a diterpenoid triepoxide isolated from the Chinese plant Tripterygium wilfordii Hook F [1], is known to possess anti-inflammatory, immunosuppressive, and anti-tumor activities [2-4]. Numerous in vitro studies have revealed cytotoxic effects of TL in a wide range of human malignancies including breast $[5,6]$, pancreatic $[7,8]$, gastric $[6,9]$, colorectal $[10,11]$ and non-small cell lung carcinoma (NSCLC) $[4,12]$. TL has also been reported to inhibit growth of solid tumors in vivo [4, 6]. Specifically, our group has shown that TL suppresses tumor growth in an established xenograft nude mouse model [4]. We recently provided evidence that TL decreases cell proliferation and induces apoptosis in NSCLC via inhibiting NF-kB signaling [4]. Moreover, our group has demonstrated that p53 deficiency exacerbates the cytotoxic effects of TL in
NSCLC and that TL impairs mitochondria function in a p53-dependent manner by SIRT-3 regulation [12]. The SIRT proteins are a family of class III histone deacetylases that includes seven isoforms (SIRT1-7) in mammalian cells. These stress-responsive proteins, which have been implicated in carcinogenesis, are thought to have both tumor promoter and tumor suppressor functions depending upon the type of cancer [13, 14]. Furthermore, epigenetic regulation of Sirt mRNA, particularly Sirt-1 [15-18], by non-coding MicroRNAs (miRNAs) is believed to play a prominent role in cell proliferation, development and cancer formation [14]. miRNAs, a class of small noncoding RNAs involved in gene regulation, are known to be aberrantly expressed in human cancer cells (reviewed in [19]).

In recent years, considerable attention has focused on Caveolin-1 (CAV-1), a key scaffolding/signaling protein, in driving cancer progression and metastasis 
[20, 21]. As with many other cancers [22], overexpression of CAV-1 protein is associated with aggressiveness and metastasis, as well as poor clinical prognosis, in human lung cancer [23, 24]. Additionally, decreased expression of CAV-1 is associated with NSCLC drug-resistance $[25,26]$. However, despite its known anti-proliferative/ pro-apoptotic effects on NSCLC in vitro, the potential impact of TL on CAV-1 expression in lung cancer cells is unknown.

Because the precise mechanism(s) of the anti-lung cancer activities of TL are incompletely defined, we sought to determine if TL treatment of lung cancer cells affects both CAV-1 expression and overall cell viability. In this study, we found that TL induces Akt-mediated apoptosis in A549 and NCI-H460 NSCLC by direct down-regulation of CAV-1 mRNA/protein expression. We also demonstrate that TL significantly up-regulates miR-204-5p expression in both cell lines, resulting in decreased CAV-1 expression. These TL-mediated effects were significantly blocked by both siRNA and pharmacologic inhibition of SIRT-1 and SIRT-3 enzyme activity. Our in vitro findings suggest a novel mechanistic pathway by which TL triggers NSCLC cell death via CAV-1 down-regulation.

\section{RESULTS}

\section{Triptolide downregulates CAV-1 and SIRT- 1 mRNA/protein expression in human A549/ NCI-H460 cells}

Our earlier studies demonstrated that TL treatment of A549 and NCI-H460 NSCLC cells significantly decreased viability in a dose-dependent manner $[4,12]$. Because CAV1 over-expression is believed to be a key element in cancer development, we employed real-time reverse transcription PCR (RT-PCR) to explore whether TL affects Cav-1mRNA expression in vitro. Compared to control-treated cells, 50/100 nM TL treatment caused a significant reduction in mRNA expression in both A549 and H460 cells (Figure 1A). Specifically, in A549 cells, RT-PCR analysis showed an approximate 2 -fold $(45 \%)$ decrease $(p<0.05)$ in Cav-1 mRNA transcript levels with 50/100 nM TL, while decreased Cav-1 mRNA transcript levels in NCI-H460 cells were more pronounced with approximately 3 -fold $(65 \%)$ $(p<0.01)$ and 4 -fold $(75 \%)(p<0.01)$ reduction with 50 $\mathrm{nM}$ and $100 \mathrm{nM}$ TL treatment, respectively. In agreement with mRNA expression results, immunoblotting revealed a significant reduction $(\sim 30 \%, p<0.05)$ in CAV-1 protein expression following $100 \mathrm{nM}$ TL treatment of both A549 and NCI-H460 cells (Figure 1B and 1C).

Next, we assessed mRNA/protein expression of SIRT-1, a major deacetylase believed to play a protumorigenic role in lung cancer [25] and shown to be required for CAV-1 expression [17]. Similarly to CAV1 expression results, we observed that TL treatment of A549 and NCI-H460 cells significantly $(p<0.05)$ reduced Sirt-1 mRNA and protein expression compared to non-treated cells. Sirt-1 mRNA transcript levels were reduced approximately $33 \%(p<0.05)$ in A549 cells with 50/100 nM TL treatment, while NCI-H460 Sirt-1 mRNA levels decreased significantly in a dose-dependent manner with approximate decreases of nearly 2 -fold (50\%) $(50 \mathrm{nM}, p<0.01)$ and 10 -fold $(90 \%)(100 \mathrm{nM}, p<0.01)$. (Figure 2A). Consistent with both CAV-1 protein and Sirt1 mRNA expression results, immunoblot analysis indicated nearly $30 \%(p<0.05)$ and $40 \%(p<0.05)$ reduction, respectively, in SIRT-1 protein expression following 50 $\mathrm{nM}$ and $100 \mathrm{nM}$ TL treatment of both A549 and NCI-H460 cells (Figure 2B and 2C). Altogether, these results indicate that TL significantly decreased both mRNA and protein expression of CAV-1 and SIRT-1 in NSCLC cells.

\section{SIRT-1 and SIRT-3 inhibition block triptolide- induced downregulation of $\mathrm{CAV}-1$ expression in human A549/NCI-H460 cells}

To further elucidate (and confirm) the apparent TLinduced mechanism for Sirt-1-mediated downregulation of Cav-1, we conducted two Sirt-1 mRNA inhibitory studies: 1) Pre-treatment with specific Sirt-1 siRNA and 2) Pharmacologic pre-treatment with EX-527, a selective Sirt1 activity inhibitor $[27,28]$ and asked whether deficiency of Sirt-1 could prevent CAV-1 protein downregulation. As shown by immunoblot analysis in Figure 3A, specific siRNA-mediated downregulation of Sirt-1 mRNA impeded TL-induced CAV-1 protein down-regulation in both A549 $(p>0.05)$ and NCI-H460 cells $(p<0.05)$. In addition, pre-treatment with $10 \mu \mathrm{M}$ EX-527 significantly $(p<0.05)$ blocked TL-induced CAV-1 protein down-regulation in both cell lines (Figure 3B and 3C). As expected, CAV1 protein expression significantly $(p<0.05)$ decreased following TL treatment in control-treated (i.e., scrambled siRNA/No EX-527) cells (Figure 3C).

Our earlier study [12] supports an essential role of SIRT-3 for TL-induced impairment of mitochondrial function and associated apoptosis in A549 and NCI-H460 lung cancer cells. In a similar manner as SIRT-1 experiments above, we inhibited Sirt-3 mRNA expression via siRNA and Sirt-3 activity via nicotinamide chemical treatment [29] to determine whether SIRT-3 is involved in TL-mediated Cav-1 downregulation. Consistent with our previous findings [12], inhibition via Sirt-3 mRNA expression (Figure 3D and 3F; $p<0.05$, NCI-H460) or SIRT-3 enzyme activity (Figure 3E and 3F; $p<0.05$, A549/NCI-H460) significantly inhibited TL-induced CAV-1 protein down-regulation following TL treatment, indicating SIRT-3 appears necessary for TL/CAV-1 pathway in both NSCLC cells. Taken together, results from these inhibitor studies suggest SIRT-1 and SIRT-3 play important roles in mediating TL-induced downregulation of CAV-1 protein expression in A549 and NCI-H460 lung cancer cells. 
Triptolide upregulates miR204-5p expression, causing downregulation of Cav-1 and Sirt-1 mRNA expression in human A549/NCI-H460 cells

Over the last decade, non-coding MicroRNAs (miRNAs) have garnered considerable attention for their potential use as a tool for cancer diagnosis and prognosis. Indeed, previous studies in human malignancies have shown Sirt-1 to be a target gene of miR204-5p [25-27]. To explore the potential effect of TL on miR204-5p expression in NSCLC, we examined miR204-5p transcript levels in A549 and NCI-H460 cells using RT-PCR. As shown in
Figure 4A, we found that TL treatment significantly (100 $\mathrm{nM}, p<0.05)$ upregulated miR204-5p RNA expression in a dose-dependent manner (2.5-30-fold) in A549 cells versus non-treated cells. In H460 cells, miR204-5p RNA expression was elevated modestly $(\sim 1.7$-fold, $p>0.05)$ compared to control-treated cells following 50/100 nM TL treatment. As expected, mRNA expression of both Cav1 and Sirt- 1 significantly $(p<0.05)$ decreased following treatment with TL (Figure 4B). To further validate these findings, A549 and NCI-H460 cells transfected with miR204-5p inhibitor (prior to TL treatment) demonstrated increased ( $p<0.05$, A549) Cav-1 (Figure 5A) mRNA transcript expression, along with decreased $(p<0.05$,

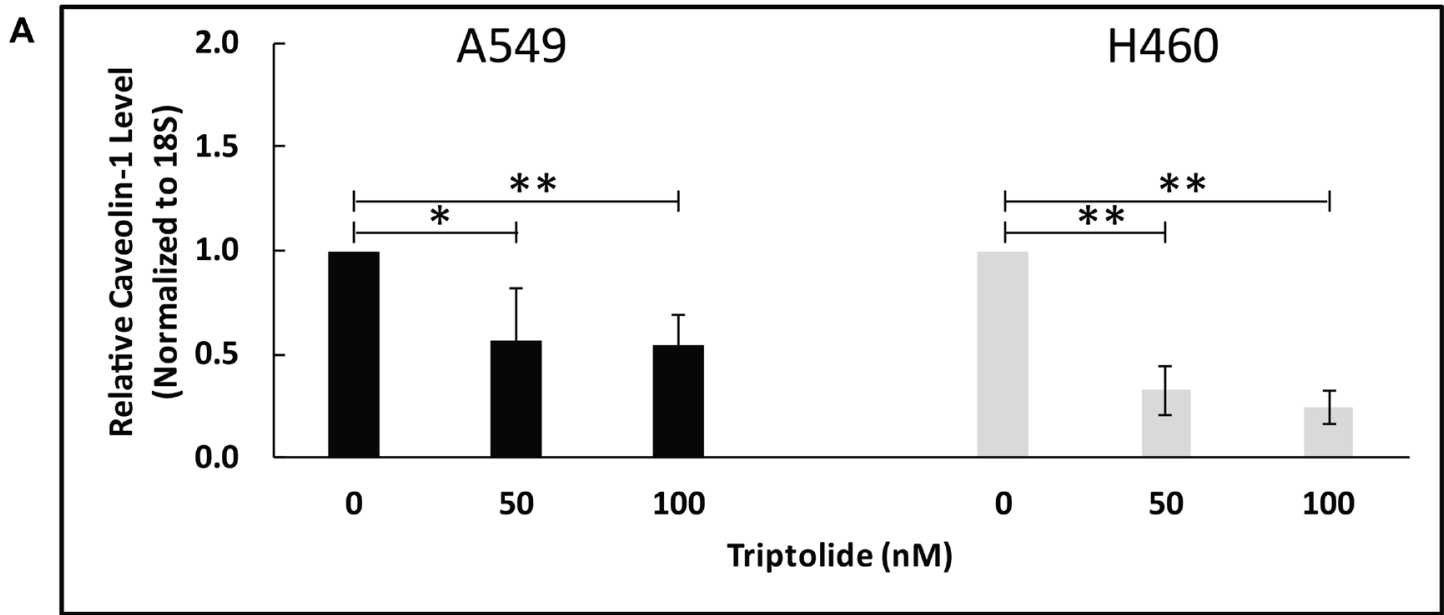

B
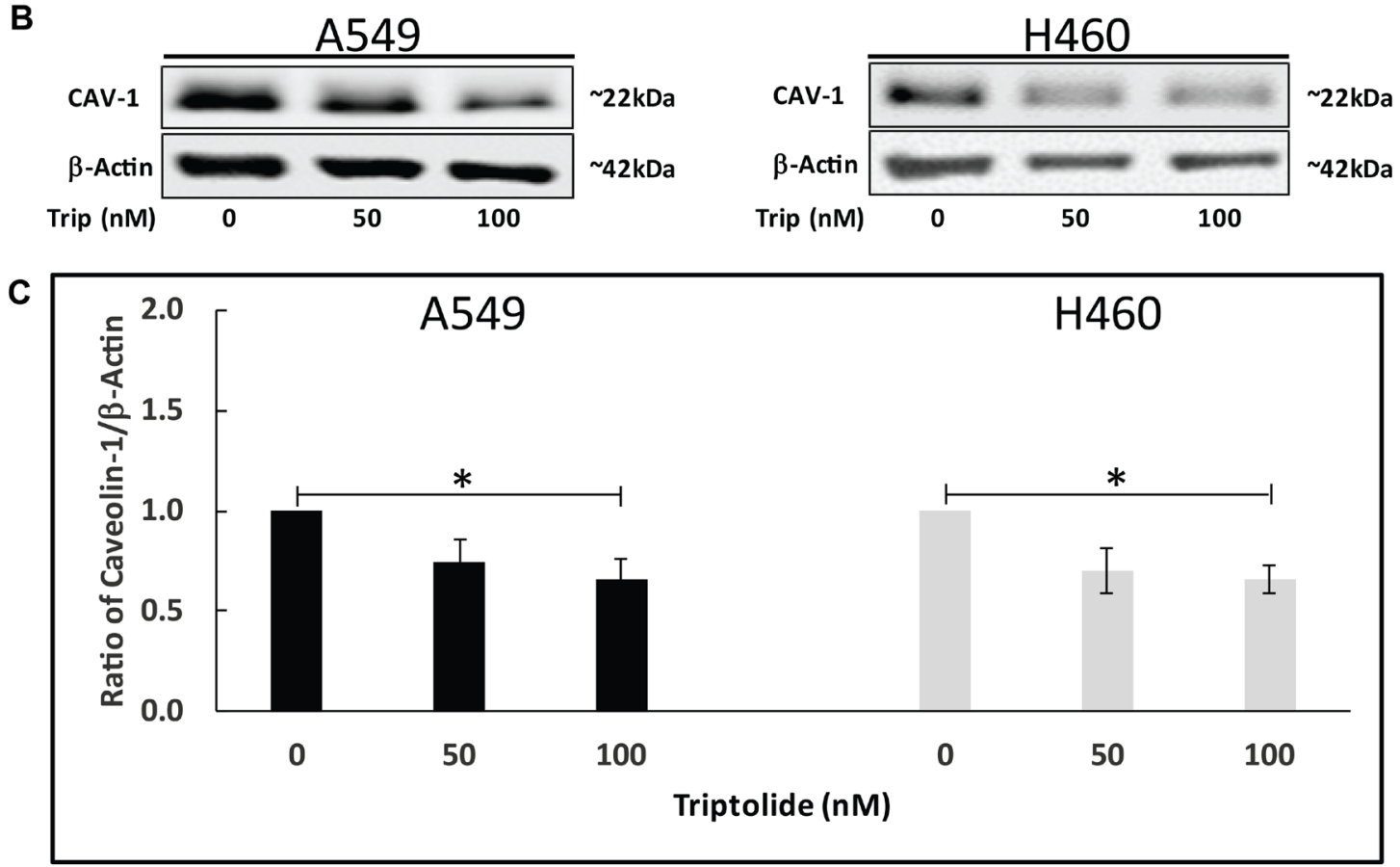

Figure 1: TL downregulated Cav-1 mRNA/protein expression in NSCLC. A549 and NCI-H460 cells were treated for $20 \mathrm{~h} \pm$ $50 \mathrm{nM} / 100 \mathrm{nM}$ TL. (A) Real-time RT-PCR was performed to analyze mRNA expression of Cav-1 target gene. Values were normalized with $18 \mathrm{~S}$ rRNA expression and are expressed as mean $\pm \mathrm{SD} . n=5-7$. "indicates significantly different $(p<0.05)$. (B) Representative immunoblot and (C) quantitation of CAV-1 protein expression in A549 and NCI-H460 cells. Protein quantity was normalized to $\beta$-Actin. Data are presented as mean \pm SD. $n=3-4 .{ }^{*}$ indicates significantly different $(p<0.05)$. ${ }^{* *}$ indicates significantly different $(p<0.01)$. 
A549) mRNA expression of miR204-5p (Figure 5B), in comparison to control (scrambled siRNA) treated cells. No significant differences in mRNA levels of Cav-1 and miR204-5p were exhibited with control (scrambled siRNA) treated cells \pm TL versus TL alone (non-siRNA)treated cells (data not shown). Overall, these findings suggest that miR204-5p plays a role in TL-induced downregulation of Cav-1/Sirt-1/-3 in A549 and NCI-H460 NSCLC cells.

\section{TL induces Akt/Bax-dependent apoptosis in human A549/NCI-H460 cells}

Previously, we have demonstrated that: 1) TL promotes apoptosis in various NSCLC by regulating key apoptotic factors [4] and 2) TL impairs mitochondria function in a $\mathrm{p} 53$-dependent manner by SIRT-3 regulation [12]. To investigate the underlying mechanisms of TL/ CAV-1-induced apoptosis, we analyzed protein expression of key markers associated with the mitochondrial apoptosis pathway following treatment with $50 / 100 \mathrm{nM}$ TL. As shown in Figure 6A, both A549 and NCI-H460 cells expressed considerable levels of endogenous phosphorylated Akt (Ser473), suggesting Akt activation in these cells. Following TL treatment, we observed a significant $(p<0.05)$ attenuation of Akt phosphorylation, along with significantly $(p<0.05)$ decreased CAV-1 protein expression in both cell lines (Figure 6A and 6B). Examination of further downstream targets indicated TL treatment significantly $(p<0.05)$ increased the
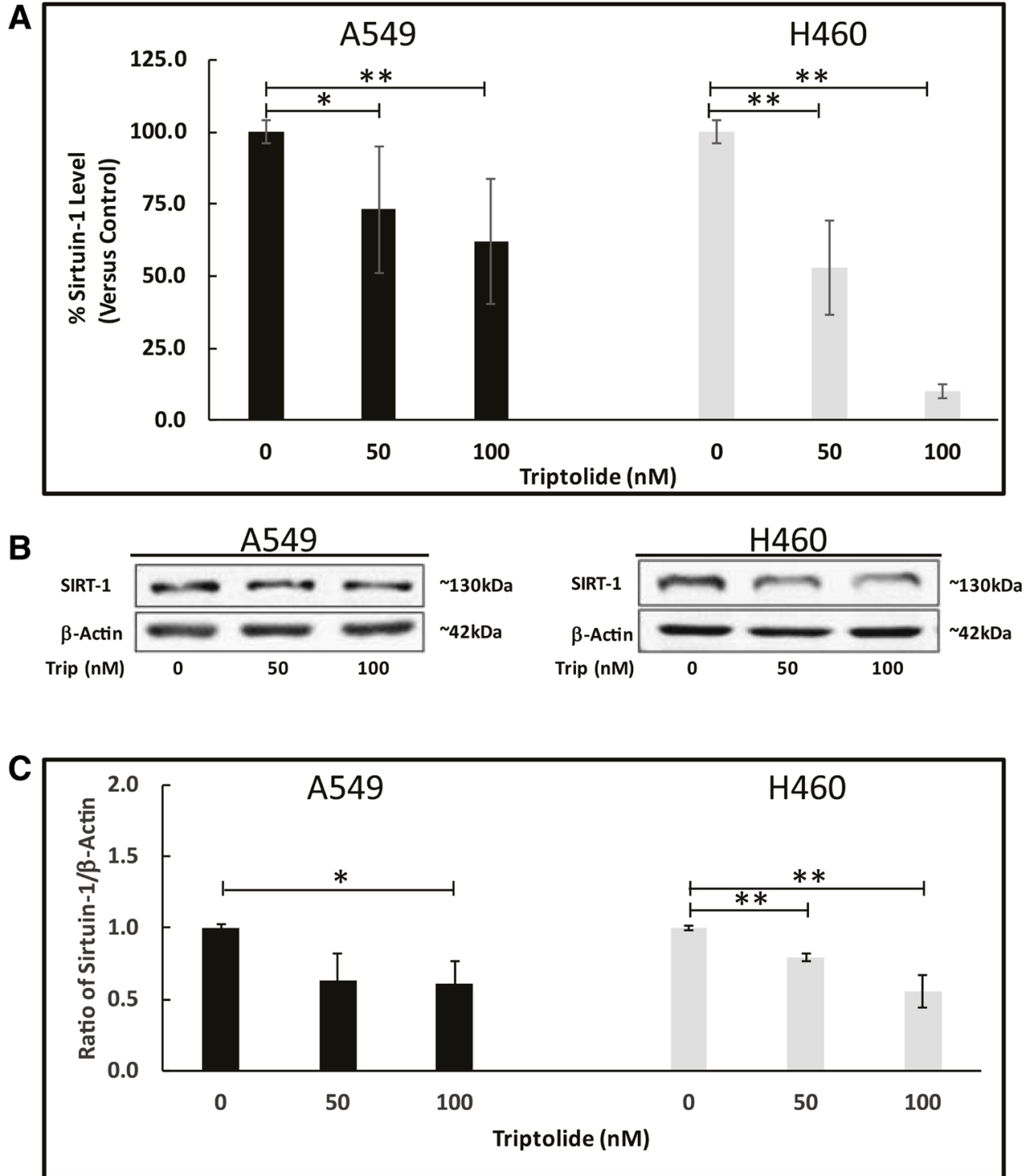

Figure 2: TL downregulated Sirt-1 mRNA/protein expression in NSCLC. A549 and NCI-H460 cells were treated for $20 \mathrm{~h} \pm$ $50 \mathrm{nM} / 100 \mathrm{nM}$ TL. (A) Real-time RT-PCR was performed to analyze mRNA expression of Sirt-1 target gene. Values were normalized with $18 S$ rRNA expression and are expressed as mean \pm SD. $n=6-8$. *indicates significantly different $(p<0.05)$. (B) Representative immunoblot and (C) quantitation of SIRT-1 protein expression in A549 and NCI-H460 cells. Protein quantity was normalized to $\beta$-Actin. Data are presented as mean \pm SD. $n=3-4 .{ }^{*}$ indicates significantly different $(p<0.05) .{ }^{*}$ indicates significantly different $(p<0.01)$. 
(pro-apoptotic/anti-apoptotic) Bax/Bcl-2 ratio and activated the mitochondrial apoptotic pathway, inducing cleaved caspase-3 and cleaved-PARP (Figure 6A-6C). Collectively, these results suggest that apoptotic effects of TL in A549 and NCI-H460 NSCLC cells are mediated via the activation of the classical Akt/Bax mitochondrial signaling pathway.

\section{DISCUSSION}

Triptolide (TL) has shown considerable promise as an effective anti-proliferative/-neoplastic agent both in vitro and in vivo. Clinically, such encouraging effects are currently being evaluated in both national and international, multi-center phase I and II trials (clinicaltrials.gov) using Minnelide which is the watersoluble prodrug developed for clinical use. Previously, we have shown that TL suppresses solid tumor growth in mice via apoptotic induction [4]. However, because its molecular mechanism(s) of action are not completely understood, we sought to pursue a deeper understanding of the basic molecular interactions responsible for TL's anti-growth/pro-apoptotic effects in vitro. In the present study, we explored the potential involvement of CAV-1, a key signaling protein associated with cancer progression, regarding TL-induced cytotoxicity in A549 and NCI-H460 lung cancer cells. Our results indicate that TL significantly decreases CAV-1 mRNA/protein expression, causing apoptosis in A549 and NCI-H460 cells by activation of the classical Akt/Bcl-2-mediated mitochondrial apoptosis pathway. In addition, our data demonstrate that CAV-1 down-regulation, coupled with cellular apoptosis, could be significantly blocked by inhibition of miR204-5p, SIRT-1 and SIRT-3.

CAV-1 is an integral membrane protein involved in cell signaling and transport. For many human tumors, CAV-1 upregulation influences cancer cell survival and growth, thus favoring tumor progression [30]. In lung cancer, overexpression of CAV-1 protein is known to be associated with aggressiveness and metastasis, as well as poor clinical prognosis [23, 24]. In addition, Han et al. [31] showed that CAV-1 knockdown caused a significant reduction in cell growth of paclitaxel-resistant lung cancer A549 cells. More recently, studies by Liu and coworkers [32] demonstrated that knockdown of CAV-1 in A549 cells enhanced cisplatin-triggered cancer death. Because of the growth inhibition and associated apoptotic effects of TL in a wide variety of epithelial and hematological cancer cell lines [5-11], including NSCLC cells [4, 12], we investigated the potential changes in CAV-1 mRNA/ protein expression following TL treatment in A549 and NCI-H460 lung cancer cells.

Our in vitro data showed that 50/100 nM TL treatment of A549 and NCI-H460 cells caused a significant
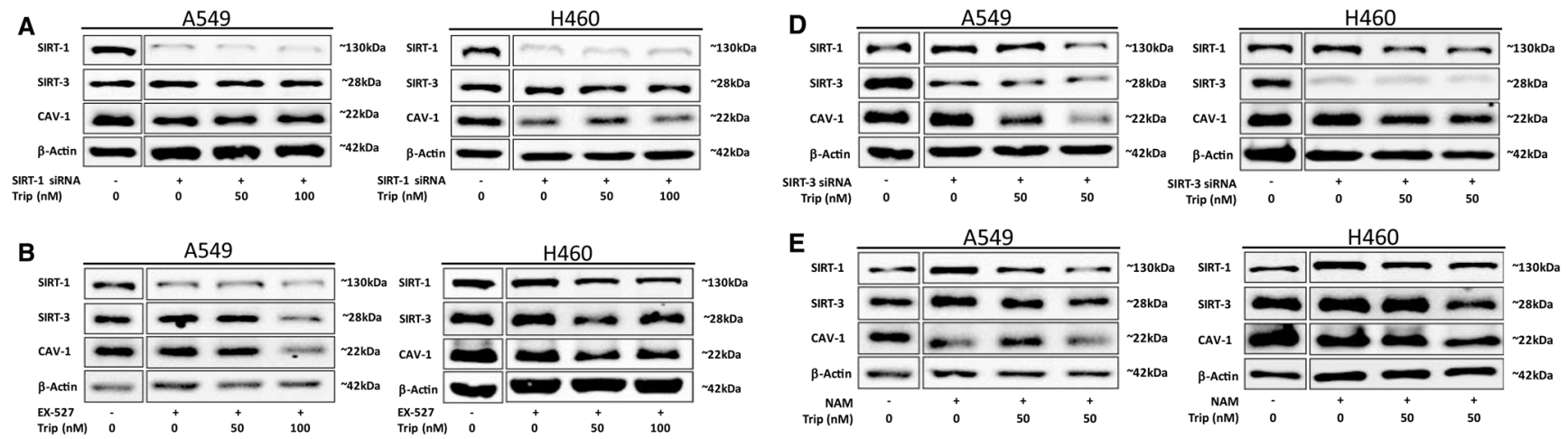

C
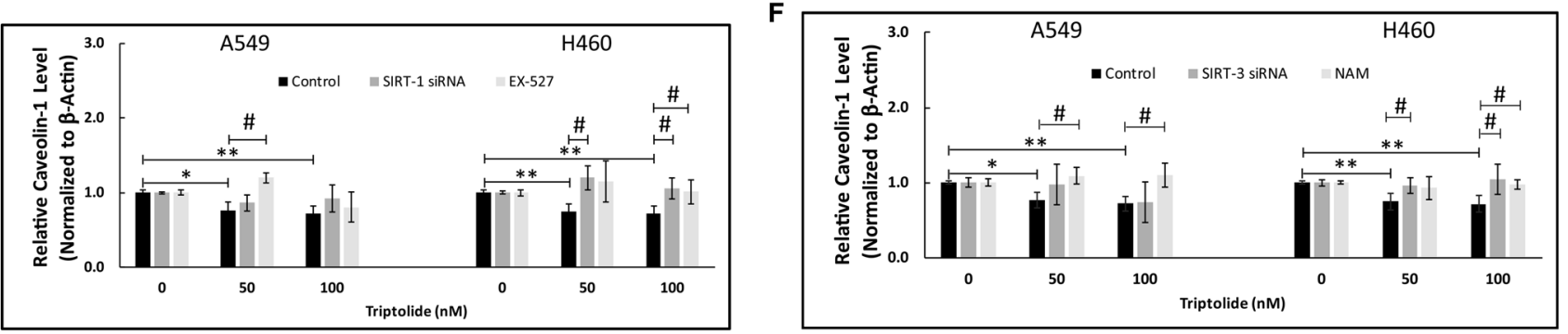

Figure 3: SIRT-1/-3 siRNA knockdown and EX-527/NAM treatment inhibited TL-induced downregulation of CAV-1 protein expression in NSCLC. A549 and NCI-H460 cells were treated for 4-6 h with Opti-MEM (low-serum) medium containing 80pmoles Sirt-1 siRNA (A), $10 \mu \mathrm{M}$ EX-527 (B), 80pmoles Sirt-3 siRNA (D) or 10mM NAM (E). After 24 h (siRNA) or 4/6 h (EX-527/ NAM), cells were incubated for $20 \mathrm{~h} \pm 50 \mathrm{nM} / 100 \mathrm{nM}$ TL. Representative immunoblots (A, B, D, E) and quantitation (C, F) for CAV-1 protein expression. Protein quantity was normalized to $\beta$-Actin. Data are presented as mean \pm SD. $n=3-4$. *indicates significantly different ( $p<0.05$ vs non-TL treated). ${ }^{* *}$ indicates significantly different ( $p<0.01$ vs non-TL treated). ${ }^{*}$ indicates significantly different $(p<0.05$ vs control). 
$(p<0.05)$ reduction in both CAV-1 mRNA (Figure 1A) and protein (Figure 1B and 1C) expression in both A549 and NCI-H460 cells. Specifically, decreased Cav-1 mRNA transcript levels in NCI-H460 cells were more pronounced ( $\sim 3-4$-fold) than in A549 cells ( 2-fold), though effects on decreased protein expression were similar for both cell lines. In agreement with Han et al. [31] and Liu et al. [32] findings, these observations suggest that CAV-1 downregulation plays an important role regarding TL-induced cytotoxicity in A549 and NCI-H460 NSCLC cells.

Sirtuins are members of the class III histone deacetylase family of enzymes that influence the cellular responses to genomic instability by regulating the cell cycle, DNA repair, cell survival and apoptosis, and thus have pivotal roles in cancer initiation and progression [33]. In 2001, SIRT-1 was the first sirtuin shown to be involved in cancer via repression of p53 activity [34, 35]. Moreover, it has recently been demonstrated that SIRT1 is required for Cav-1 expression [17] and that CAV1 is a direct binding partner of SIRT-1 under oxidative stress conditions [36]. As with CAV-1 mRNA/protein expression, we found that TL treatment of A549 and NCI-H460 cells significantly $(p<0.05)$ reduced Sirt1 mRNA and protein expression versus control-treated cells (Figure 2), consistent with previous findings [17]. Compared to A549 cells, NCI-H460 Sirt-1 mRNA transcript expression was particularly sensitive to TL as evidenced by the significant $(p<0.01)$ dose-dependent decrease in expression (Figure 2A), though decreased protein expression profiles ( $\sim 35 \%$ reduction) were comparable for both cell lines (Figure 2B and 2C). These data strongly imply that SIRT-1 is necessary for CAV-1 expression and implicated a potential link between SIRT$1 / \mathrm{CAV}-1$ expression in mediating the effects of TL.

Our previously published findings [12] established an essential role of SIRT-3 for TL-induced impairment of mitochondrial function and associated apoptosis in A549 and NCI-H460 lung cancer cells. To further substantiate the roles of SIRT-1 and SIRT-3 involved in TL-triggered CAV-1 repression, we treated both cell lines with SIRT1/-3 siRNA and with the enzyme inhibitors EX-527/ nicotinamide. As shown by Western blot (Figure 3A and 3D) and protein quantitation (Figure 3C and 3F) analyses, specific siRNA-mediated knockdown of either Sirt-1 or Sirt-3 effectively blocked TL-induced CAV1 protein down-regulation in both A549 and NCI-H460 cells. Quantitation of CAV-1 protein expression indicated that siRNA knockdown of Sirt-1/-3 mRNA generated significant $(p<0.05)$ effects only in NCI-H460 cells (Figure $3 \mathrm{C}$ and $3 \mathrm{~F}$ ). It is plausible that reduced transfection efficiency, decreased siRNA sensitivity and/or insufficient cell exposure time to Sirt-1/-3 siRNA prior to TL treatment may explain these abridged CAV-1 expression effects in A549 cells. Treatment of A549 cells with increased (> $80 \mathrm{nM}$ ) Sirt-1/-3 siRNA may significantly reduce CAV1 expression, although based upon SIRT-1/-3 endogenous (non-treated) protein (Figures 2 and 3) and mRNA levels (data not shown), we observed that A549 and NCI-H460 cells have very similar expression profiles.

Additionally, opposing effects of TL and SIRT-3 knockdown may be responsible for the disparate findings in A549 cells. Specifically, Sirt-3 mRNA knockdown suppressed CAV-1 protein expression downregulation, but TL treatment concomitantly decreased Sirt- 1 mRNA/ protein expression (Figure 2) resulting in decreased CAV1 protein expression. Consequently, it would be expected that under these conditions, Sirt-3 mRNA knockdown effects would be muted regarding suppression of CAV1 protein expression. Such effects were not observed in NCI-H460 cells under Sirt-3 mRNA knockdown conditions perhaps due to uncharacterized inherent cell line differences, though future studies with doubleknockdown Sirt-1/-3 using low $(<25 \mathrm{nM})$ doses of TL would help elucidate the mechanistic contributions of each SIRT protein. Such low TL doses have been reported to have minimal effects on A549 growth and viability after $24 \mathrm{~h}$ treatment $[4,37]$.

Furthermore, pre-treatment of both cell lines with either $10 \mu \mathrm{M}$ EX-527 or $10 \mathrm{mM}$ NAM significantly ( $p$ $<0.05$ ) inhibited TL-induced CAV-1 protein downregulation (Figure $3 \mathrm{C}$ and $3 \mathrm{~F}$ ), suggesting that (under our conditions) SIRT enzyme inhibition was a more effective means than siRNA pre-treatment to block CAV1 protein down-regulation. Nonetheless, these inhibitor studies indicate that SIRT-1 and SIRT-3 play pivotal roles in mediating TL-induced down-regulation of CAV1 protein expression in A549 and NCI-H460 lung cancer cells, further supporting the importance of SIRT-3 in TLmediated cytotoxicity [12].

Because of its wide-spread apoptotic effects in cancer cells, we were interested in screening TL-treated lung cancer cells for cDNA profile expression changes. Microarray studies (data not published) demonstrated that following treatment of A549 cells with $50 \mathrm{nM}$ and $100 \mathrm{nM}$ TL for $20 \mathrm{~h}$, one of the most highly-expressed gene transcripts identified was miR204-5p. MicroRNAs (miRNAs) are a family of small non-coding RNAs that regulate numerous biological processes, and their expression has been found to be highly dysregulated in cancer cells (reviewed in [19]). Regarding lung cancer, Hu et al. [38] identified four specific miRNA signatures that were significantly associated with overall survival of lung cancer. Also, several more recent in vitro studies have revealed a significant reduction in NSCLC cell proliferation with specific miRNA overexpression $[39,40]$.

Our in vitro studies indicated that $50 / 100 \mathrm{nM} \mathrm{TL}$ treatment of A549 cells caused significantly increased miR204-5p RNA expression in a dose-dependent manner $(p<0.01$ at $100 \mathrm{nM})$ versus non-treated cells (Figure 4A), whereas miR204-5p RNA expression was elevated modestly ( 2-fold, $p>0.05)$ in NCI-H460 cells compared to DMSO-treated cells. More importantly, 
mRNA expression of both Cav-1 and Sirt-1 significantly $(p<0.05)$ decreased concomitantly with miR204-5p upregulation (Figure 4B) implying that elevated miR204$5 \mathrm{p}$ RNA is associated with TL-induced cytotoxicity in A549 and NCI-H460 lung cancer cells. One potential reason for the discrepancy in TL-induced miR204$5 p$ expression between the two cell lines could be the endogenous transcript levels for each cell line. Relative to basal 18S RNA expression, our RT-PCR studies indicated that $\mathrm{H} 460$ cells possess nearly 500 - to 1000 -fold increased basal expression of miR204-5p than A549 cells (data not shown). As a result, any induction of miR204-5p RNA by TL treatment would be more pronounced in A549 cells compared to NCI-H460 cells. Notably, treatment of H460 cells with a higher dose $(200 \mathrm{nM})$ of TL did not increase miR204-5p transcript expression above the level observed at $100 \mathrm{nM}$ TL (data not shown).

To further confirm and validate a link between miR204-5p expression and CAV-1 expression, we demonstrated that transfection of A549 and NCI-H460 cells with a specific miR204-5p inhibitor (prior to TL treatment) effectively repressed the TL-induced inhibitory effect on Cav-1 mRNA transcript expression (Figure 5A). These findings are consistent with reports of Cav-1 being a target of miR204-5p [17, 41-44]. More specifically, our data substantiate very recent findings by Huang et al. [44] that downregulation of miR-204 expression is responsible for CAV-1 overexpression in cisplatin-resistant A549 cells. Taken together, our findings indicate that: 1) Cav-1 is a likely target of miR204-5p and 2) miR204-5p plays a key role in TL-induced down-regulation of Cav-1/Sirt-1/-3 in A549 and NCI-H460 NSCLC cells.

In attempt to further investigate the precise molecular mechanism of TL-induced cytotoxicity, protein expression of several downstream signaling molecules was analyzed by immunoblotting following 18-24 h TL treatment of A549 and NCI-H460 cells. We found that TL-mediated Cav-1 knockdown significantly $(p<0.05)$ reduced the phosphorylation level of Akt (Ser473) in both cell lines (Figure 6). Additionally, Cav-1 repression by
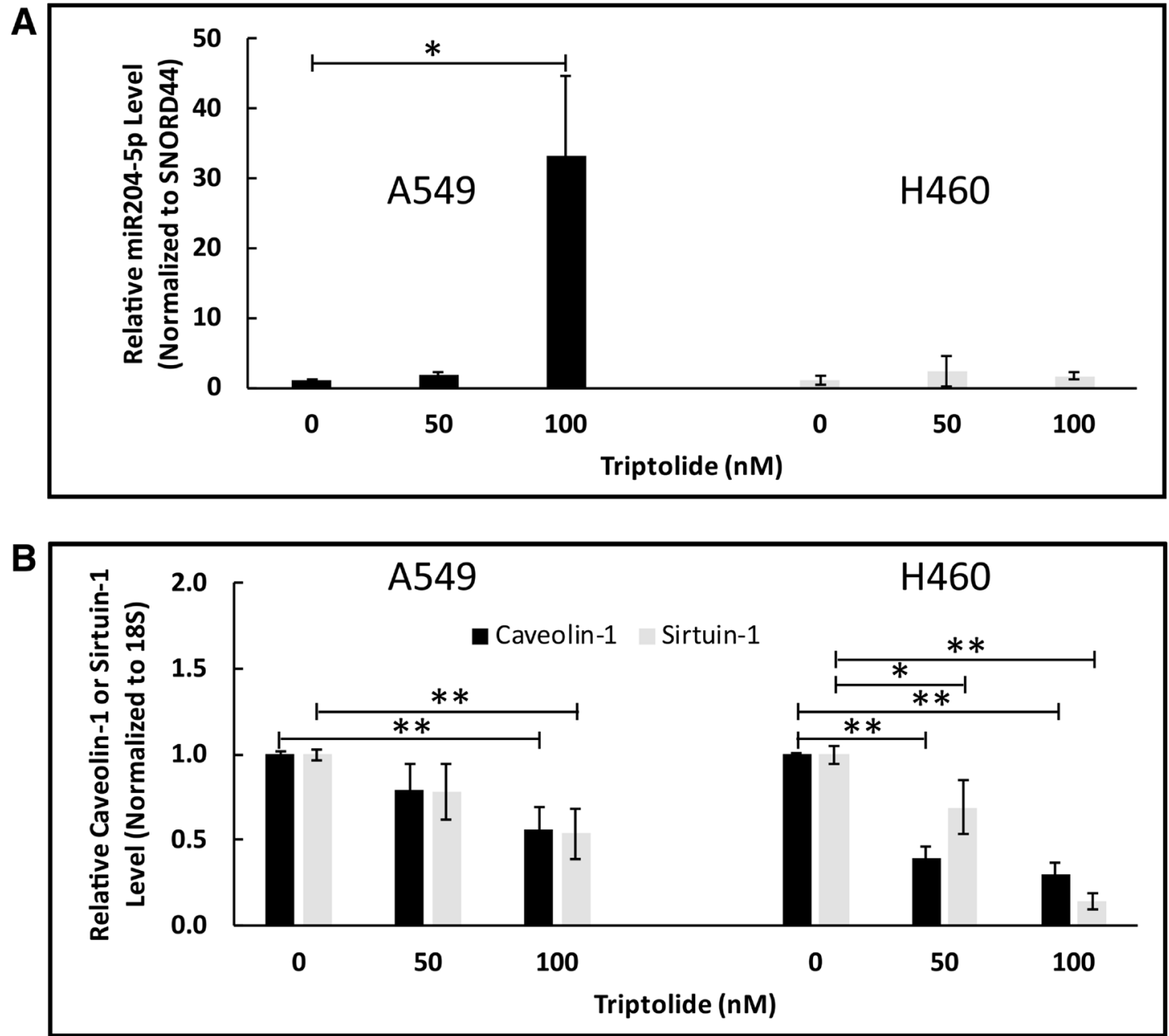

Figure 4: TL upregulated miR204-5p mRNA expression in NSCLC. A549 and NCI-H460 cells were treated for $20 \mathrm{~h} \pm 50$ $\mathrm{nM} / 100 \mathrm{nM}$ TL. Real-time RT-PCR was performed to analyze mRNA expression of (A) miR204-5p and (B) Cav-1/Sirt-1 target genes. Values were normalized with either (A) Snord44 or (B) $18 S$ rRNA expression and are expressed as mean \pm SD. $n=3-4$. *indicates significantly different $(p<0.05) .{ }^{* *}$ indicates significantly different $(p<0.01)$. 
TL treatment significantly $(p<0.05)$ increased the (proapoptotic/anti-apoptotic) $\mathrm{Bax} / \mathrm{Bcl}-2$ ratio and activated the canonical mitochondrial apoptotic pathway, inducing the Caspase- 3 cascade effect and the expression of cleaved PARP ( $p<0.05$, Figure 6 ). These observations are consistent with our previous study [4], which showed both significantly increased Caspase- 3 enzyme activity and cleaved-PARP production after $24 \mathrm{~h} \mathrm{100/200} \mathrm{nM} \mathrm{TL}$ treatment of A549 and NCI-H460 cells. Also, our current data contradict previous reports [45] of unobserved apoptosis (despite $\sim 50 \%$ cell death) in A549 cells treated for $24 \mathrm{~h}$ with $200 \mathrm{nM}$ tripchlorolide, a derivative of TL. Moreover, our findings are in agreement with previous studies that have demonstrated activation of the Akt signaling pathway/apoptosis with similar time/TL dosage treatment of cancer cells [7], including A549 cells [46-49]. Overall, our study indicated that TL promoted apoptosis in NSCLC cells through Akt pathway signaling.

Our study is not without its limitations. For example, numerous studies have firmly demonstrated that Cav-1 is a direct target of miR204-5p [17, 41-44], thus miR-204-5p could directly down-regulate protein expression of CAV1 in NSCLC. To our knowledge, this direct connection has not been demonstrated in NSCLC though based upon our findings, CAV-1 over-expression studies using SIRT1 or SIRT-3 knockout cells would be a viable means to test this hypothesis. Also, double-knockdown SIRT-1/-3 using low $(<25 \mathrm{nM})$ doses of TL would help elucidate the mechanistic contributions of each SIRT protein. Furthermore, several studies have reported that in human cancers, including NSCLC, the JAK1/STAT3 pathway (which was not examined here) is blocked/inhibited upon TL treatment. Thus, this pathway is a possibility of future exploration for drug development in the treatment of NSCLC. Lastly, our group has previously shown that TL suppresses tumor growth in an established xenograft nude mouse model. Analysis by RNA-Seq on these tumor tissues would provide valuable information regarding additional TL-regulated genes. It should be noted that our standard approach is to perform the experiments Reviewers suggest for improvement and clarity of our work; however, due to the COVID-19 pandemic, research facilities at the University of Pittsburgh are limited in access for the unforeseeable future. Consequently, any additional experiments for this study are not feasible at this time.

In summary, our results indicate that: 1). Inhibition of Sirt-1 or Sirt-3 via siRNA or pharmacological inhibition and 2). Inhibition of miR-204-5p via siRNA are able to effectively block TL-induced CAV-1 protein downregulation in both A549 and NCI-H460 NSCLC cell lines. These findings strongly suggest a link between miR-204-5p
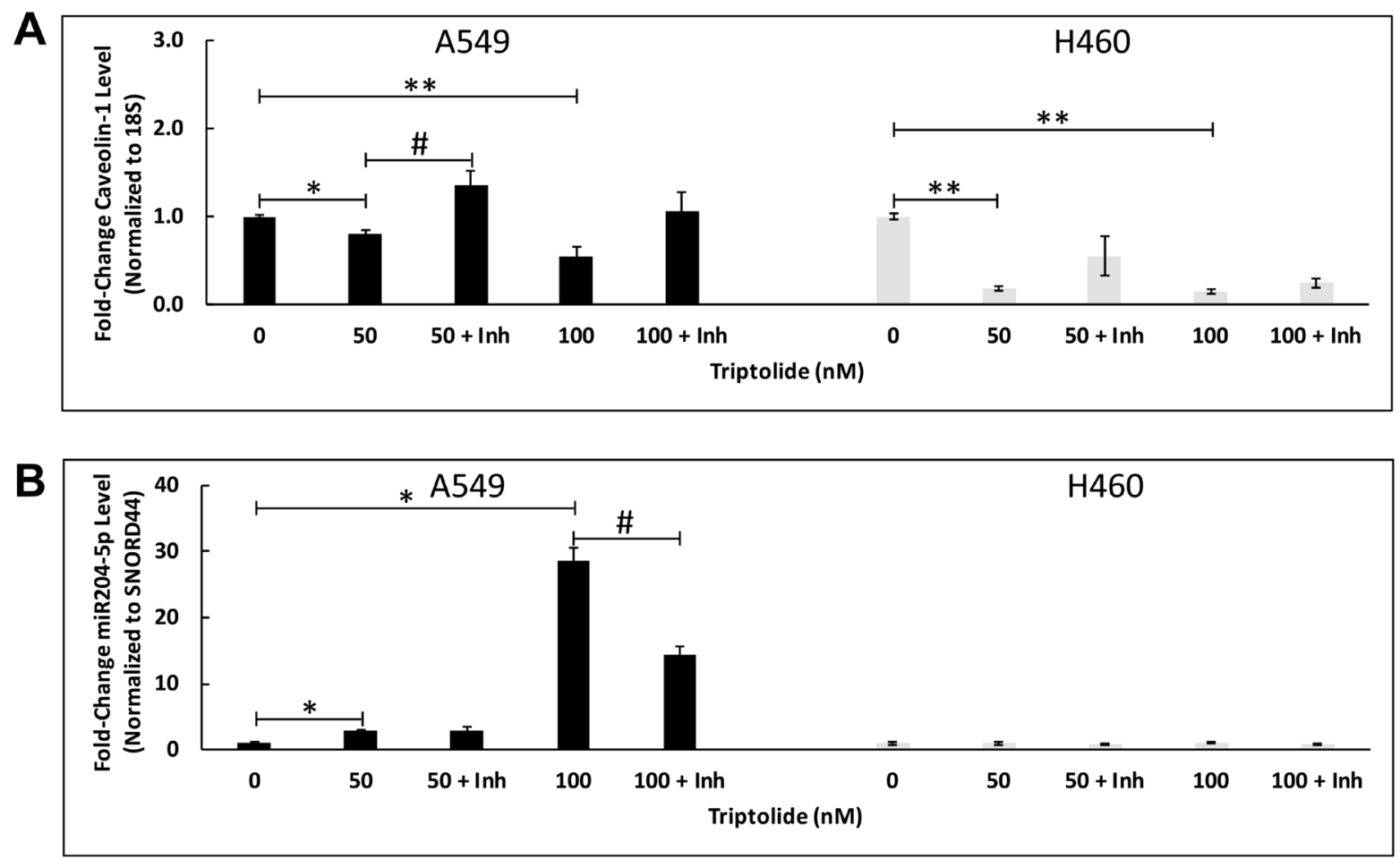

Figure 5: miR204-5p inhibitor blocked TL-induced downregulation of Cav-1 mRNA expression in NSCLC. A549 and NCI-H460 cells were first treated for $\sim 24 \mathrm{~h}$ with Opti-MEM (low-serum) medium containing miR204-5p inhibitor or scrambled control miRNA, then incubated for $20 \mathrm{~h} \pm 50 \mathrm{nM} / 100 \mathrm{nM}$ triptolide. Real-time RT-PCR was performed to analyze mRNA expression of (A) Cav-1 and (B) miR204-5p target genes. Values were normalized with either (A) $18 S$ rRNA or (B) Snord44 expression and expressed as mean \pm SD. $n=3 .{ }^{*}$ indicates significantly different ( $p<0.05$ vs non-treated). ${ }^{* *}$ indicates significantly different $\left(p<0.01\right.$ vs non-TL treated). ${ }^{*}$ indicates significantly different $(p<0.05$ vs TL alone). 
and SIRT-1:-3/CAV-1 expression in mediating the apoptotic effects of TL in NSCLC and indicate a novel mechanism by which TL, via miR204-5p up-regulation and associated CAV1 down-regulation, triggers the activation of mitochondriamediated apoptosis in NSCLC (Figure 7). Mechanistically,
TL decreases phosphorylation of Akt (Ser473), causing Bcl2 down-regulation and Bax up-regulation, culminating in caspase- 3 activation and cleavage of PARP. In this scenario, nuclear full-length (FL) SIRT-3, following TL treatment of NSCLC (i.e., cellular stress), likely mediates Cav-1 mRNA
A

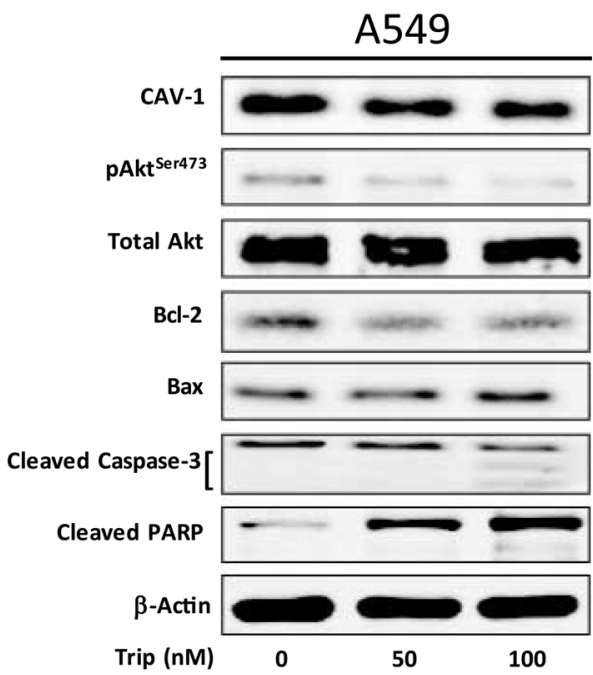

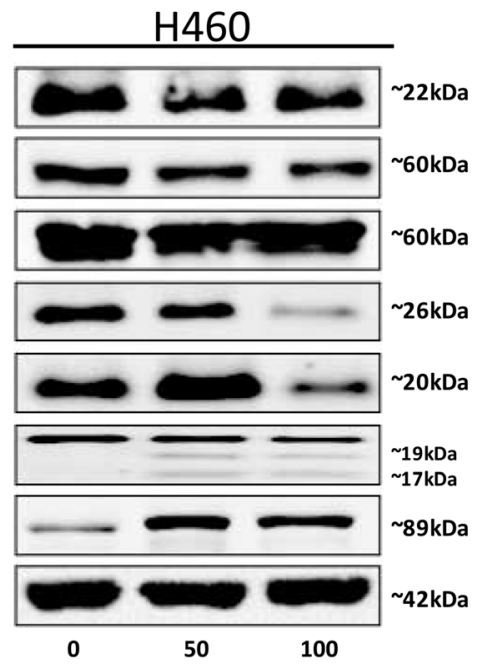

B
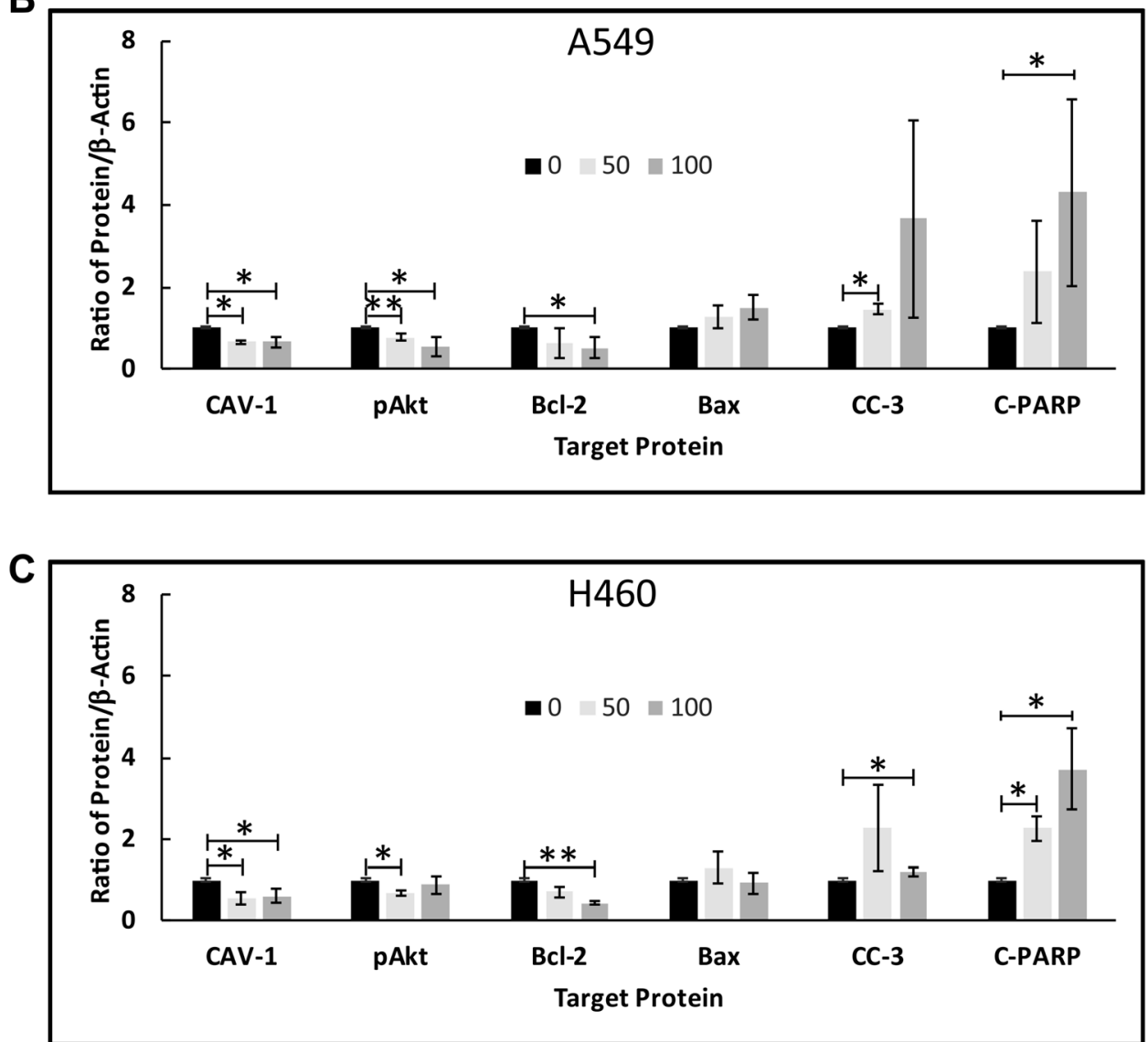

Figure 6: TL induced Akt activation in NSCLC. A549 and NCI-H460 cells were treated for $18-24 \mathrm{~h} \pm 50 \mathrm{nM} / 100 \mathrm{nM}$ TL. Representative immunoblots (A) and quantitation (B, C) for CAV-1, pAkt (Ser473), Total Akt, Bcl-2, Bax, Cleaved caspase-3 (CC-3) and Cleaved-PARP (C-PARP) protein expression. Protein quantity was normalized to $\beta$-Actin. Data are presented as mean $\pm \mathrm{SD} . n=3-4$. ${ }^{*}$ indicates significantly different $(p<0.05) .{ }^{* *}$ indicates significantly different $(p<0.01)$. 
down-regulation either directly or indirectly. Overall, this study proposes new insight into the mechanistic basis of TL-induced mitochondria-mediated apoptosis involving miR204-5p/CAV-1 and provides a rationale for future clinical investigation of the therapeutic efficacy of TL in NSCLC patients.

\section{MATERIALS AND METHODS}

\section{Cell culture conditions}

The human NSCLC cell lines A549 (K-Ras mutant, adenocarcinoma) and NCI-H460 (K-Ras mutant, adenocarcinoma) were obtained from the American Type Culture Collection (Rockville, MD, USA). Cells were cultured in a humidified incubator at $37^{\circ} \mathrm{C}$ and $5 \% \mathrm{CO} 2$ and grown in RPMI 1640 medium (Life Technologies Inc, Carlsbad, CA, USA) supplemented with $10 \%$ heatinactivated fetal bovine serum, $50 \mathrm{U} / \mathrm{mL}$ penicillin and 50 $\mu \mathrm{g} / \mathrm{mL}$ streptomycin (Life Technologies Inc). Cell media was replaced every $48 \mathrm{~h}$ and cells were split upon 80-90\% confluence.

\section{Reagents and antibodies}

Triptolide (TL), purchased from Calbiochem (NJ, USA), was dissolved in Dimethyl sulfoxide (DMSO, Sigma-Aldrich, St. Louis, MO, USA) to a stock solution of $1 \mathrm{mg} / \mathrm{ml}(2.77 \mathrm{mM})$ and stored at $-20^{\circ} \mathrm{C}$. Nicotinamide (NAM), obtained from Sigma-Aldrich, was prepared fresh prior to each experiment by dissolving in $1 \times$ phosphate buffered saline (PBS) to a stock solution of $122 \mathrm{mg} / \mathrm{mL}$ (1M). EX-527 (Sigma-Aldrich) was dissolved in 100\% DMSO to a stock solution of $20 \mathrm{mM}$ and stored at $-20^{\circ} \mathrm{C}$. Cells were stimulated with indicated doses of TL, NAM or EX-527 in complete media. DMSO alone was included to serve as a control. All data were acquired from at least 3 independent experiments.

The following primary antibodies were utilized for immunoblotting: rabbit polyclonal anti-caveolin-1 (N-20,

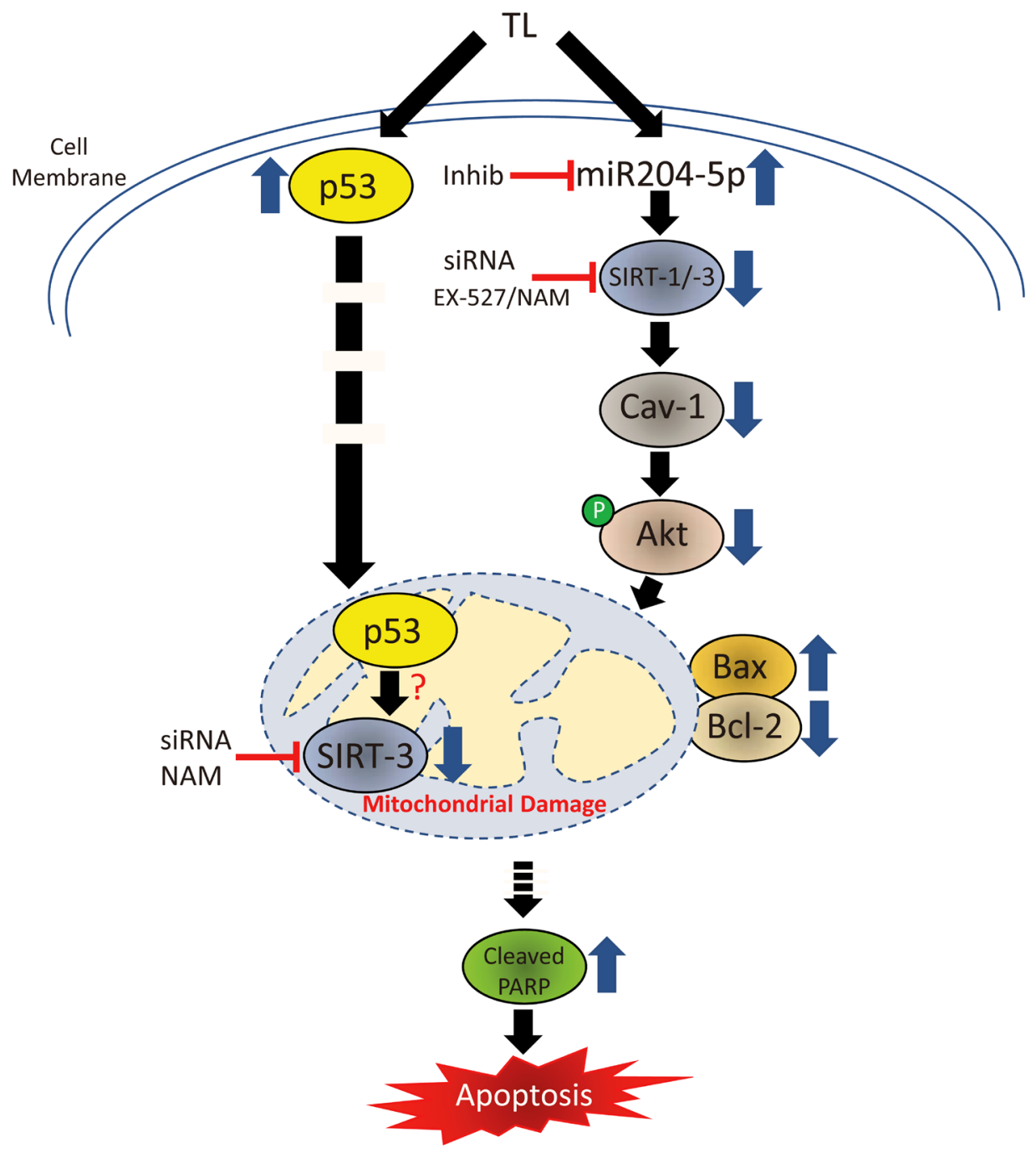

Figure 7: Signal transduction cascade mediating TL-induced apoptosis in NSCLC. TL decreases protein expression of both SIRT-1 and SIRT-3 through independent pathways resulting in mitochondrial dysfunction in NSCLC. 
1:1000, Santa Cruz Biotechnology, Santa Cruz, CA, USA), mouse monoclonal anti $\beta$-actin (C4, 1:10,000, Santa Cruz), rabbit monoclonal anti-SIRT-1 (D1D7, 1:1000, Cell Signaling Technology, Danvers, MA, USA), rabbit monoclonal antiSIRT-3 (C73E3, 1:1000, Cell Signaling), rabbit polyclonal anti-phospho-Akt [Ser473] (1:1000, Cell Signaling), rabbit monoclonal anti-Akt [pan] (C67E7, 1:1000, Cell Signaling), rabbit monoclonal anti-Bcl-2 (D55G8, 1:1000, Cell Signaling), rabbit polyclonal anti-Bax (2772, 1:1000, Cell Signaling), rabbit monoclonal anti-cleaved caspase-3 [Asp175] (5A1E, 1:1000, Cell Signaling) and rabbit monoclonal anti-cleaved poly (ADP-ribose) polymerase (PARP) [Asp214] (D64E10, 1:1000, Cell Signaling).

\section{siRNA-mediated knockdown of Sirt-1 and Sirt-3}

Silencer select siRNA against human Sirt-1 and Sirt-3 along with the negative (non-specific) control-pool were purchased from Life Technologies Inc. Knockdown of Sirt-1 and Sirt-3 was performed similarly as previously described [12]. Briefly, cells were seeded into 6-well plates $(300,000$ cells/well) approximately $24 \mathrm{~h}$ before transfection in RPMI medium. On the day of transfection, $80 \mathrm{nM}$ (40pmoles) Sirt-1, Sirt-3 or non-specific siRNA was first incubated with Lipofectamine 2000 (Invitrogen, Carlsbad, CA, USA) at room temperature for $30 \mathrm{~min}$, then added to cells ( $\sim 70 \%$ confluency) in Opti-MEM (low-serum) medium (Life Technologies Inc). After $4 \mathrm{~h}$, the medium was aspirated and replaced with fresh RPMI medium. Twenty-four hours later the medium was aspirated and replaced with fresh RPMI medium $\pm 50 \mathrm{nM}$ or $100 \mathrm{nM}$ TL and cells cultured for an additional $20 \mathrm{~h}$ at $37^{\circ} \mathrm{C}$. The knocked-down genes were confirmed by immunoblotting. All data were acquired from at least 3 independent experiments.

\section{SIRT-1/SIRT-3 enzyme inhibition by EX-527/ nicotinamide}

In brief, cells were seeded into 6 -well plates $(300,000$ cells/well) approximately $24 \mathrm{~h}$ before treatment. Cells ( $\sim 70 \%$ confluency) were then treated with either $10 \mu \mathrm{M}$ $\mathrm{EX}-527$ or $10 \mathrm{mM}$ nicotinamide for $4 \mathrm{~h}$ at $37^{\circ} \mathrm{C}$. Control cells were treated with medium containing $1 \times$ PBS or DMSO. After $4 \mathrm{~h}$, the medium was aspirated and replaced with fresh RPMI medium $\pm 50 \mathrm{nM}$ or $100 \mathrm{nM}$ TL and cells cultured for an additional $20 \mathrm{~h}$ at $37^{\circ} \mathrm{C}$. Inhibited gene expression was confirmed by immunoblotting. All data were acquired from at least 3 independent experiments.

\section{miR204-5p mRNA inhibition}

MISSION miRNA inhibitor targeting
human miR204-5p (Mature sequence: 5'-UUCC
CUUUGUCAUCCUAUGCCU-3') along with scrambled
(control) miRNA were purchased from Sigma-Aldrich.

Briefly, cells were seeded into 6 -well plates $(300,000$ cells/well) approximately $24 \mathrm{~h}$ before transfection. On the day of transfection, $40 \mathrm{nM}$ (20pmoles) of anti-miR204-5p or control miRNA was first incubated with Lipofectamine 2000 (Invitrogen) at room temperature for $30 \mathrm{~min}$, then added to cells $(\sim 70 \%$ confluency) in Opti-MEM (lowserum) medium (Life Technologies Inc) at $37^{\circ} \mathrm{C}$. After $6 \mathrm{~h}$, the medium was aspirated and replaced with fresh RPMI medium. Twenty-four hours later medium was aspirated and replaced with fresh RPMI medium $\pm 50 \mathrm{nM}$ or $100 \mathrm{nM}$ TL and cells cultured for an additional $20 \mathrm{~h}$ at $37^{\circ} \mathrm{C}$. All data were acquired from at least 3 independent experiments.

\section{Western blotting}

Attached cells were collected by gentle scraping for protein extraction. Whole cell lysates were prepared by boiling cells for $10 \mathrm{~min}$ in a $2 \%$ SDS buffer $(2 \% \mathrm{SDS}$, $50 \mathrm{mM}$ Tris- $\mathrm{HCl} \mathrm{pH} 6.8,10 \%$ glycerol) supplemented with protease inhibitors (Sigma-Aldrich). Proteins were resolved on $8-10 \%$ SDS-PAGE followed by transfer to $0.2 \mu \mathrm{m}$ nitrocellulose membranes (Bio-Rad Laboratories, Hercules, CA, USA). Western blotting was performed by incubating with appropriate primary antibodies followed by secondary antibodies conjugated to far-red fluorescent dyes (IRDye-680 and -800) and detection using the Odyssey LI-COR system (LI-COR Biotechnology, Lincoln, NE, USA). Blot quantifications were performed using LI-COR software. All data were acquired from at least 3 independent experiments.

\section{Real-Time RT-PCR}

Total RNA and miRNA from cultured cells was isolated using miRNeasy Mini-Kit (Qiagen, Valencia, CA, USA) and cDNA was synthesized using qScript $^{\mathrm{TM}}$ microRNA cDNA Synthesis Kit (VWR International, Radnor, PA, USA). Real-time PCR was performed using PowerUp SYBR Green Master Mix (ThermoFisher Scientific, Waltham, MA, USA) to monitor the amplification on an ABI-7500 PCR machine. The following primers were used: Human Caveolin-1 (Forward-CACATCTGGGCAGTTGTACC; Reverse-CACAGACGGTGTGGACGTAG), miR2045p (Forward-CGCTTCCCTTTGTCATCCTA), Human Sirt-1 (Forward-TTGTTATTGGGTCTTCCCTCAAAG; Reverse-GACATCACAGTCTCCAAGAAGC), Human Sirt-3 (Forward-GAGCTTCTGGGCTGGACAGA; Reverse-TGGGATGTGGATGTCTCCTATG),

Human SNORD44 (Forward-GCAAATGCTG ACTGAACATGAA) and Human 18S (ForwardTAGAGGGACAAGTGGCGTTC; Reverse-CGCTGA GCCAGTCAGTGT). Real-time PCR assays were run in triplicate in MicroAmp Optical 384-well reaction plates on an ABI-7500 Real Time PCR System using the PowerUp 
SYBR Green Master Mix (ThermoFisher Scientific). RTPCR reaction mixtures of a total volume of $10 \mu \mathrm{L}$ contained $5 \mu \mathrm{L}$ of $2 \times \mathrm{SYBR}$ Green Master Mix, $0.5 \mu \mathrm{L}$ each of $10 \mu \mathrm{M}$ forward and reverse primers, and $2-3 \mu \mathrm{L}$ cDNA. Cycling was performed using the default conditions of the Sequence Detection System software version 1.3 (Life Technologies Inc.): $10 \mathrm{~min}$ at $95^{\circ} \mathrm{C}$, followed by 40 rounds of $15 \mathrm{sec}$ at $95^{\circ} \mathrm{C}$ and $1 \mathrm{~min}$ at $60^{\circ} \mathrm{C}$. Data were normalized to either the reference gene $18 S$ or Snord44 (miR204-5p studies), a small non-coding RNA located within the nucleolus. All data were acquired from at least 3 independent experiments.

\section{Statistical methods and analyses}

All data are representative of at least three independent experiments. Results are expressed as mean \pm SD. For comparison to DMSO/non-TL-treatment, a onesample $t$-test was conducted $(\mu=1)$. For siRNA/enzyme inhibitor studies, differences were compared using twosampled $t$-test. All analyses utilized $\alpha=0.05$, two sided. Analyses were conducted in R (v. 3.5.2).

\section{Abbreviations}

Akt: RAC-alpha serine/threonine-protein kinase; CAV-1: Caveolin-1; EX-527: 6-Chloro-2,3,4,9-tetrahydro1H-Carbazole-1-carboxamide; miRNA: MicroRNA; NAM: Nicotinamide; NSCLC: Nonsmall-cell lung cancer; PARP: Poly (ADP-ribose) polymerase; SIRT: Sirtuin; TL: Minnelide/Triptolide.

\section{Author contributions}

Conceptualization and Design of Study: BJP, AK, JD; Data curation: BJP, AK, JD; Data analysis and interpretation: BJP, AK, SB, JR, KN, JD; Methodology: BJP, AK, SB, KN; Manuscript: Original draft: BJP, JD; Manuscript: Review \& editing: BJP, AK, SB, JR, KN, JD.

\section{ACKNOWLEDGMENTS}

The authors acknowledge Drs. Mark. T. Gladwin and Sruti Shiva for shared use of laboratory equipment. The authors also wish to thank Drs. Ashok Saluja and Vikas Dudeja and their research groups for their collaborations as part of this work.

\section{CONFLICTS OF INTEREST}

The authors declare that they have no competing interests.

\section{FUNDING}

Funding for this research was supported by the Harriet Norgren Lung Cancer Research Fund and institutional funds (University of Pittsburgh and Mayo Clinic Arizona).

\section{REFERENCES}

1. Kupchan SM, Court WA, Dailey RG Jr, Gilmore CJ, Bryan RF. Triptolide and tripdiolide, novel antileukemic diterpenoid triepoxides from Tripterygium wilfordii. J Am Chem Soc. 1972; 94:7194-7195. https://doi.org/10.1021/ ja00775a078. [PubMed]

2. Ziaei S, Halaby R. Immunosuppressive, anti-inflammatory and anti-cancer properties of triptolide: A mini review. Avicenna J Phytomed. 2016; 6:149-164. [PubMed]

3. Liu Q. Triptolide and its expanding multiple pharmacological functions. Int Immunopharmacol. 2011; 11:377-383. https:// doi.org/10.1016/j.intimp.2011.01.012. [PubMed]

4. Rousalova I, Banerjee S, Sangwan V, Evenson K, McCauley JA, Kratzke R, Vickers SM, Saluja A, D'Cunha J. Minnelide: a novel therapeutic that promotes apoptosis in non-small cell lung carcinoma in vivo. PLoS One. 2013; 8:e77411. https://doi.org/10.1371/journal.pone.0077411. [PubMed]

5. Gao H, Zhang Y, Dong L, Qu XY, Tao LN, Zhang YM, Zhai JH, Song YQ. Triptolide induces autophagy and apoptosis through ERK activation in human breast cancer MCF-7 cells. Exp Ther Med. 2018; 15:3413-3419. https://doi. org/10.3892/etm.2018.5830. [PubMed]

6. Yang S, Chen J, Guo Z, Xu XM, Wang L, Pei XF, Yang J, Underhill CB, Zhang L. Triptolide inhibits the growth and metastasis of solid tumors. Mol Cancer Ther. 2003; 2:65-72. [PubMed]

7. Kim MJ, Lee TH, Kim SH, Choi YJ, Heo J, Kim YH. Triptolide inactivates Akt and induces caspase-dependent death in cervical cancer cells via the mitochondrial pathway. Int J Oncol. 2010; 37:1177-1185. https://doi.org/10.3892/ ijo_00000769. [PubMed]

8. McGinn O, Gupta VK, Dauer P, Arora N, Sharma N, Nomura A, Dudeja V, Saluja A, Banerjee S. Inhibition of hypoxic response decreases stemness and reduces tumorigenic signaling due to impaired assembly of HIF1 transcription complex in pancreatic cancer. Sci Rep. 2017; 7:7872. https:// doi.org/10.1038/s41598-017-08447-3. [PubMed]

9. Jiang XH, Wong BC, Lin MC, Zhu GH, Kung HF, Jiang SH, Yang D, Lam SK. Functional p53 is required for triptolide-induced apoptosis and AP-1 and nuclear factorkappaB activation in gastric cancer cells. Oncogene. 2001; 20:8009-8018. https://doi.org/10.1038/sj.onc.1204981. [PubMed]

10. Johnson SM, Wang X, Evers BM. Triptolide inhibits proliferation and migration of colon cancer cells by inhibition of cell cycle regulators and cytokine receptors. J Surg Res. 2011; 168:197-205. https://doi.org/10.1016/j. jss.2009.07.002. [PubMed]

11. Liu J, Shen M, Yue Z, Yang Z, Wang M, Li C, Xin C, Wang Y, Mei Q, Wang Z. Triptolide inhibits colon-rectal cancer 
cells proliferation by induction of G1 phase arrest through upregulation of p21. Phytomedicine. 2012; 19:756-762. https://doi.org/10.1016/j.phymed.2012.02.014. [PubMed]

12. Kumar A, Corey C, Scott I, Shiva S, D'Cunha J. Minnelide/ Triptolide Impairs Mitochondrial Function by Regulating SIRT3 in P53-Dependent Manner in Non-Small Cell Lung Cancer. PLoS One. 2016; 11:e0160783. https://doi. org/10.1371/journal.pone.0160783. [PubMed]

13. Carafa V, Altucci L, Nebbioso A. Dual Tumor Suppressor and Tumor Promoter Action of Sirtuins in Determining Malignant Phenotype. Front Pharmacol. 2019; 10:38. https://doi.org/10.3389/fphar.2019.00038. [PubMed]

14. O'Callaghan C, Vassilopoulos A. Sirtuins at the crossroads of stemness, aging, and cancer. Aging Cell. 2017; 16:12081218. https://doi.org/10.1111/acel.12685. [PubMed]

15. Choi SE, Kemper JK. Regulation of SIRT1 by microRNAs. Mol Cells. 2013; 36:385-392. https://doi.org/10.1007/ s10059-013-0297-1. [PubMed]

16. Hou M, Zuo X, Li C, Zhang Y, Teng Y. Mir-29b Regulates Oxidative Stress by Targeting SIRT1 in Ovarian Cancer Cells. Cell Physiol Biochem. 2017; 43:1767-1776. https:// doi.org/10.1159/000484063. [PubMed]

17. Kassan M, Vikram A, Kim YR, Li Q, Kassan A, Patel HH, Kumar S, Gabani M, Liu J, Jacobs JS, Irani K. Sirtuin 1 protects endothelial Caveolin-1 expression and preserves endothelial function via suppressing miR-204 and endoplasmic reticulum stress. Sci Rep. 2017; 7:42265. https://doi.org/10.1038/srep42265. [PubMed]

18. Milner J. Cellular regulation of SIRT1. Curr Pharm Des. 2009; 15:39-44. https://doi.org/10.2174/138161209787185841. [PubMed]

19. Peng Y, Croce CM. The role of MicroRNAs in human cancer. Signal Transduct Target Ther. 2016; 1:15004. https://doi.org/10.1038/sigtrans.2015.4. [PubMed]

20. Chatterjee M, Ben-Josef E, Thomas DG, Morgan MA, Zalupski MM, Khan G, Andrew Robinson C, Griffith KA, Chen CS, Ludwig T, Bekaii-Saab T, Chakravarti A, Williams TM. Caveolin-1 is Associated with Tumor Progression and Confers a Multi-Modality Resistance Phenotype in Pancreatic Cancer. Sci Rep. 2015; 5:10867. https://doi.org/10.1038/srep10867. [PubMed]

21. Nwosu ZC, Ebert MP, Dooley S, Meyer C. Caveolin-1 in the regulation of cell metabolism: a cancer perspective. Mol Cancer. 2016; 15:71. https://doi.org/10.1186/s12943-0160558-7. [PubMed]

22. Burgermeister E, Liscovitch M, Rocken C, Schmid RM, Ebert MP. Caveats of caveolin-1 in cancer progression. Cancer Lett. 2008; 268:187-201. https://doi.org/10.1016/j. canlet.2008.03.055. [PubMed]

23. Ho CC, Kuo SH, Huang PH, Huang HY, Yang CH, Yang PC. Caveolin-1 expression is significantly associated with drug resistance and poor prognosis in advanced non-small cell lung cancer patients treated with gemcitabine-based chemotherapy. Lung Cancer. 2008; 59:105-110. https://doi. org/10.1016/j.lungcan.2007.07.024. [PubMed]
24. Zhan P, Shen XK, Qian Q, Wang Q, Zhu JP, Zhang Y, Xie HY, $\mathrm{Xu}$ CH, Hao KK, Hu W, Xia N, Lu GJ, Yu LK. Expression of caveolin-1 is correlated with disease stage and survival in lung adenocarcinomas. Oncol Rep. 2012; 27:1072-1078. https://doi.org/10.3892/or.2011.1605. [PubMed]

25. Han L, Liang XH, Chen LX, Bao SM, Yan ZQ. SIRT1 is highly expressed in brain metastasis tissues of non-small cell lung cancer (NSCLC) and in positive regulation of NSCLC cell migration. Int J Clin Exp Pathol. 2013; 6:2357-2365. [PubMed]

26. Shi Y, Tan SH, Ng S, Zhou J, Yang ND, Koo GB, McMahon KA, Parton RG, Hill MM, Del Pozo MA, Kim YS, Shen HM. Critical role of CAV1/caveolin-1 in cell stress responses in human breast cancer cells via modulation of lysosomal function and autophagy. Autophagy. 2015; 11:769-784. https://doi.org/10.1080/15548627.2015.1034411. [PubMed]

27. Gertz M, Fischer F, Nguyen GT, Lakshminarasimhan M, Schutkowski M, Weyand M, Steegborn C. Ex-527 inhibits Sirtuins by exploiting their unique NAD+dependent deacetylation mechanism. Proc Natl Acad Sci U S A. 2013; 110:E2772-E2781. https://doi.org/10.1073/ pnas.1303628110. [PubMed]

28. Kim HW, Kim SA, Ahn SG. Sirtuin inhibitors, EX527 and AGK2, suppress cell migration by inhibiting HSF1 protein stability. Oncol Rep. 2016; 35:235-242. https://doi. org/10.3892/or.2015.4381. [PubMed]

29. Guan X, Lin P, Knoll E, Chakrabarti R. Mechanism of inhibition of the human sirtuin enzyme SIRT3 by nicotinamide: computational and experimental studies. PLoS One. 2014; 9:e107729. https://doi.org/10.1371/ journal.pone.0107729. [ PubMed]

30. Ketteler J, Klein D. Caveolin-1, cancer and therapy resistance. Int J Cancer. 2018; 143:2092-2104. https://doi. org/10.1002/ijc.31369. [PubMed]

31. Han F, Zhang L, Zhou Y, Yi X. Caveolin-1 regulates cell apoptosis and invasion ability in paclitaxel-induced multidrug-resistant A549 lung cancer cells. Int J Clin Exp Pathol. 2015; 8:8937-8947. [PubMed]

32. Liu Y, Fu Y, Hu X, Chen S, Miao J, Wang Y, Zhou Y, Zhang Y. Caveolin-1 knockdown increases the therapeutic sensitivity of lung cancer to cisplatin-induced apoptosis by repressing Parkin-related mitophagy and activating the ROCK1 pathway. J Cell Physiol. 2020; 235:1197-1208. https://doi.org/10.1002/ icp.29033. [PubMed]

33. Chalkiadaki A, Guarente L. The multifaceted functions of sirtuins in cancer. Nat Rev Cancer. 2015; 15:608-624. https://doi.org/10.1038/nrc3985. [PubMed]

34. Luo J, Nikolaev AY, Imai S, Chen D, Su F, Shiloh A, Guarente L, Gu W. Negative control of p53 by Sir2alpha promotes cell survival under stress. Cell. 2001; 107:137-148. https://doi.org/10.1016/S0092-8674(01)00524-4. [PubMed]

35. Vaziri H, Dessain SK, Ng Eaton E, Imai SI, Frye RA, Pandita TK, Guarente L, Weinberg RA. hSIR2(SIRT1) functions as an NAD-dependent p53 deacetylase. Cell. 2001; 107:149-159. https://doi.org/10.1016/S0092-8674(01)00527-X. [PubMed] 
36. Volonte D, Zou H, Bartholomew JN, Liu Z, Morel PA, Galbiati F. Oxidative stress-induced inhibition of Sirt1 by caveolin-1 promotes $\mathrm{p} 53$-dependent premature senescence and stimulates the secretion of interleukin 6 (IL-6). J Biol Chem. 2015; 290:4202-4214. https://doi.org/10.1074/jbc.M114.598268. [PubMed]

37. Wang G, Wang $X, X u X$. Triptolide potentiates lung cancer cells to cisplatin-induced apoptosis by selectively inhibiting the NER activity. Biomark Res. 2015; 3:17. https://doi. org/10.1186/s40364-015-0043-2. [PubMed]

38. Hu Z, Chen X, Zhao Y, Tian T, Jin G, Shu Y, Chen Y, Xu L, Zen K, Zhang C, Shen H. Serum microRNA signatures identified in a genome-wide serum microRNA expression profiling predict survival of non-small-cell lung cancer. J Clin Oncol. 2010; 28:1721-1726. https://doi.org/10.1200/ JCO.2009.24.9342. [PubMed]

39. Li M, Zhang S, Wu N, Wu L, Wang C, Lin Y. Overexpression of miR-499-5p inhibits non-small cell lung cancer proliferation and metastasis by targeting VAV3. Sci Rep. 2016; 6:23100. https://doi.org/10.1038/srep23100. [PubMed]

40. Zhou X, Tao H. Overexpression of microRNA-936 suppresses non-small cell lung cancer cell proliferation and invasion via targeting E2F2. Exp Ther Med. 2018; 16:26962702. https://doi.org/10.3892/etm.2018.6490. [PubMed]

41. Hall DP, Cost NG, Hegde S, Kellner E, Mikhaylova O, Stratton Y, Ehmer B, Abplanalp WA, Pandey R, Biesiada J, Harteneck C, Plas DR, Meller J, et al. TRPM3 and miR-204 establish a regulatory circuit that controls oncogenic autophagy in clear cell renal cell carcinoma. Cancer Cell. 2014; 26:738-753. https://doi.org/10.1016/j. ccell.2014.09.015. [PubMed]

42. Cost NG, Czyzyk-Krzeska MF. Regulation of autophagy by two products of one gene: TRPM3 and miR-204. Mol Cell Oncol. 2015; 2:e1002712. https://doi.org/10.1080/2372355 6.2014.1002712. [PubMed]

43. Luo YH, Tang W, Zhang X, Tan Z, Guo WL, Zhao N, Pang SM, Dang YW, Rong MH, Cao J. Promising significance of the association of miR-204-5p expression with clinicopathological features of hepatocellular carcinoma. Medicine (Baltimore). 2017; 96:e7545. https://doi. org/10.1097/MD.0000000000007545. [PubMed]

44. Huang G, Lou T, Pan J, Ye Z, Yin Z, Li L, Cheng W, Cao Z. MiR-204 reduces cisplatin resistance in non-small cell lung cancer through suppression of the caveolin-1/AKT/ Bad pathway. Aging (Albany NY). 2019; 11:2138-2150. https://doi.org/10.18632/aging.101907. [PubMed]

45. Chen L, Liu Q, Huang Z, Wu F, Li Z, Chen X, Lin T. Tripchlorolide induces cell death in lung cancer cells by autophagy. Int J Oncol. 2012; 40:1066-1070. https://doi. org/10.3892/ijo.2011.1278. [PubMed]

46. Meng G, Wang W, Chai K, Yang S, Li F, Jiang K. Combination treatment with triptolide and hydroxycamptothecin synergistically enhances apoptosis in A549 lung adenocarcinoma cells through PP2A-regulated ERK, p38 MAPKs and Akt signaling pathways. Int J Oncol. 2015; 46:1007-1017. https://doi.org/10.3892/ijo.2015.2814. [PubMed]

47. Xie CQ, Zhou P, Zuo J, Li X, Chen Y, Chen JW. Triptolide exerts pro-apoptotic and cell cycle arrest activity on drug-resistant human lung cancer A549/Taxol cells via modulation of MAPK and PI3K/Akt signaling pathways. Oncol Lett. 2016; 12:3586-3590. https://doi.org/10.3892/ ol.2016.5099. [PubMed]

48. Song JM, Molla K, Anandharaj A, Cornax I, O'Sullivan MG, Kirtane AR, Panyam J, Kassie F. Triptolide suppresses the in vitro and in vivo growth of lung cancer cells by targeting hyaluronan-CD44/RHAMM signaling. Oncotarget. 2017; 8:26927-26940. https://doi.org/10.18632/oncotarget.15879. [PubMed]

49. Li F, Zhao D, Yang S, Wang J, Liu Q, Jin X, Wang W. ITRAQ-Based Proteomics Analysis of Triptolide On Human A549 Lung Adenocarcinoma Cells. Cell Physiol Biochem. 2018; 45:917-934. https://doi.org/10.1159/000487286. [PubMed] 